\title{
RANCANG BANGUN TRAINER KIT HTNSJR2018A SEBAGAI INOVASI ALAT BERBASIS LABORATORIUM
}

\author{
Nelson ${ }^{1 *}$, Nurhidayah ${ }^{2}$, Helga Dwi Fahyuan ${ }^{2}$, M F Afrianto ${ }^{2}$, Mardian Peslinof $^{2}$, Suparman $^{2}$, \\ Muhammad Rido ${ }^{2}$, Jajang Nurjaman ${ }^{2}$, Frastica Deswardani ${ }^{2}$ \\ ${ }^{1}$ Program Studi Kimia, Fakultas Sains dan Teknologi, Universitas Jambi, J1. Jambi-Ma.Bulian KM 15 Mendalo Darat, Jambi, 36361 , \\ Indonesia \\ ${ }^{2}$ Program Studi Fisika, Fakultas Sains dan Teknologi, Universitas Jambi, Jl. Jambi-Ma.Bulian KM 15 Mendalo Darat, Jambi, 36361 , \\ Indonesia \\ *e-mail: nelsonnapis@yahoo.co.id
}

\begin{abstract}
ABSTRAK
Telah dilakukan pengembangan media pendidikan berupa peralatan laboratorium berupa Trainer Kit HTNSJR2018A. Pada trainer kit ini terdapat sistem sensor gas $\mathrm{SO}_{2}$ dengan menggunakan sensor MQ136. Untuk sensor akustik, jenis sensor yang digunakan adalah sensor microphone. Sementara, sensor suhu dan kelembaban akan menggunakan sensor DHT22. Hasil yang diperoleh dari pengujian yang telah dilakukan adalah pada sensor suhu dan kelembaban dimana modul penunjang telah bekerja dengan baik untuk mencatat waktu dan menampilkan data dalam format DD/MM/YYYY dan HH:MM:SS. Sensor suhu dan kelembaban telah bekerja dengan baik ditunjukkan dengan adanya perubahan respon saat sensor dipaparkan pengaruh berupa hembusan nafas, udara dari hairdyer dan aliran panas dari korek api. Sedangkan untuk sensor gas MQ136 juga telah bekerja dengan baik ditunjukkan dengan adanya perubahan respon berupa tegangan dan rasio resistansi dari sensor saat dipaparkan gas $\mathrm{SO}_{2}$ yang dihasilkan dari belerang. Kemudian, untuk sensor akustik/microphone juga telah dapat bekerja dengan baik ditunjukkan dari perubahan tegangan saat diberi nada dengan volume rendah dan volume tinggi
\end{abstract}

Kata Kunci: Trainer Kit HTNSJR2018A; Sensor MQ136; Sensor Microphone; Sensor DHT22

\section{ABSTRACT}

[Title: Trainer Kit HTNSJR2018A Design As The Tool Based Laboratory Inovation] The media for education has been developed through the making of laboratory tools, Trainer Kit HTNSJR2018A. In this tool, there is a sensor system of $\mathrm{SO}_{2}$ gas using sensor $M Q 136$. For an acoustic sensor, the sensor used is a microphone. Furthermore, a DHT22 sensor is used for the temperature and humidity sensor. This sensor works well shown by the changing of response when the sensor is presented to the air from the hairdryer. A Gas sensor, $M Q 136$, also works very well shown by the changing of response in the form of voltage and the resistance ratio when it is presented to the SO2 gas from sulfur. The microphone sensor works well too as the changing of voltage is recorded when it is presented to the tone in low and high volume.

Keywords: Trainer Kit HTNSJR2018A; Sensor MQ136; Sensor Microphone; Sensor DHT22

\section{PENDAHULUAN}

Perkembangan teknologi saat ini sangat mempengaruhi kualitas sebuah pendidikan dan nantinya juga akan berperan penting terhadap kualitas Sumber Daya Manusia (SDM). Kualitas pendidikan terhadap SDM ini sangat membutuhkan sarana dan prasarana yang baik untuk menunjang proses pembelajaran yang teratur dan berkelanjutan. Kebutuhan sarana dan prasarana akan media pendidikan pada tingkat perguruan tinggi dapat berupa fasilitas laboratorium. Media pendidikan untuk laboratorium ini haruslah berupa peralatan yang dapat membantu penggunanya memahami fenomena yang sedang diamati atau suatu besaran fisis yang sedang. Oleh karena itu, perlu dilakukan sebuah upaya untuk menginovasi sebuah peralatan yang nantinya dapat digunakan untuk kebutuhan laboratorium.

Salah satu inovasi media pendidikan untuk laboratorium adalah berupa Trainer Kit. Sebuah trainer merupakan suatu set peralatan yang merupakan gabungan antara model kerja dan mock up yang terdapat pada laboratorium yang digunakan sebagai media pendidikan untuk menunjang pembelajaran peserta didik dalam menerapkan pengetahuan atau konsep yang diperoleh dengan 
benda nyata (Hasan, 2006). Trainer kit yang akan dikembangkan nantinya akan memiliki beberapa sistem sensor. Tiap sensor itu nantinya diharapkan dapat mempermudah penggunanya untuk dapat melakukan pengukuran terhadap suatu besaran fisis (yang dimiliki dalam sistem) dan dapat menggunakan informasi hasil pengukuran tersebut sesuai dengan kebutuhan pengguna trainer kit. Trainer kit nantinya akan dirancang memiliki 3 sistem sensor, yaitu: sensor gas $\mathrm{SO}_{2}$, sensor akustik, dan sensor suhu dan kelembaban.

Sistem sensor pertama adalah sensor gas $\mathrm{SO}_{2}$. Gas $\mathrm{SO}_{2}$ merupakan gas yang menyebabkan pencemaran udara. Pencemaran udara adalah suatu kondisi dimana kualitas udara rusak dan terkontaminasi oleh zat-zat, baik yang tidak berbahaya ataupun yang berbahaya bagi tubuh manusia (Ristiana, 2013). Permasalahan pencemaran udara ini banyak terjadi di kota-kota besar, daerah padat industri, dan daerah yang mengalami kebakaran hutan. Contoh gas-gas pencemaran udara adalah seperti $\mathrm{CO}, \mathrm{CO}_{2}, \mathrm{NO}$, $\mathrm{SO}_{2}$, dan lain-lain. Gas $\mathrm{SO}_{2}$ merupakan bahan kimia yang sangat berbahaya bagi tubuh manusia. Gas ini dapat mengakibatkan gangguan pernapasan dan juga gangguan pada mata. Oleh karena itu, perlu dirancang sistem yang dapat memonitori adanya gas $\mathrm{SO}_{2}$ pada suatu lingkungan atau keadaan. Sensor yang akan digunakan adalah sensor gas MQ-136. Sensor ini merupakan komponen semikonduktor yang sangat peka terhadap gas $\mathrm{SO}_{2}$ (Treska, 2013).

Sistem kedua dalam trainer kit ini adalah berupa sensor akustik. Sesnor ini nantinya mampu mendeteksi tingkat kebisingan dalam suatu lingkungan. Kebisingan dalam kehidupan sehari-hari dapat muncul karena padatnya populasi, ramainya kendaraan, alat musik dan lain-lain. Tingkat kebisingan perlu diukur sehingga diketahui seberapa besar kekuatan yang dihasilkan oleh suatu sumber suara. Sensor akustik pada penelitian ini ialah dengan menggunakan mikrofon sebagai penangkap gelombang suara. Selanjutnya akan dikendalikan oleh mikrokontroler sehingga akan diperoleh keluaran berupa besaran desibel (dB), dimana besaran tersebut akan menunjukkan tingkat kebisingan yang ditangkap mikrofon tadi.

Terakhir adalah mengenai rancangan sistem sensor suhu dan kelembaban pada trainer kit. Suhu dan kelembaban merupakan besaran fisis yang selalu terdapat pada lingkungan. Untuk tingkat laboratorium, banyak kondisi eksperimen yang mengharuskan untuk selalu berada pada keadaan suhu dan kelembaban tertentu. Oleh sebab itu, perlu dilakukan upaya agar lingkungan eksperimen selalu berada pada kondisi yang diinginkan. Salah satunya dengan merancang sistem yang dapat menginformasikan bagi penggunanya keadaan suhu dan kelembaban lingkungan saat ekperimen sedang berjalan. Sensor suhu dan kelembaban yang digunakan disini adalah sensor DHT22.

Pada penelitian ini akan dilakukan pembuatan sebuah trainer kit HTNSJR2018A yang nantinya dapat digunakan untuk kebutuhan laboratorium, khususnya pada Laboratorium Energi dan Rekayasa Material. Pada trainer kit ini akan terdapat sistem sensor gas $\mathrm{SO}_{2}$, sensor akustik, dan sensor suhu dan kelembaban. Trainer kit ini juga nantinya akan di uji kemampuannya serta dikalibrasi dengan alat standar. Trainer kit sensor ini juga nantinya akan dirancang dengan bentuk yang lebih sederhana dan tidak terlalu besar, sehingga lebih ringan dan praktis.

\section{METODE}

\section{Perancangan dan Pembuatan Alat}

Trainer kit ini tersusun dari beberapa sensor utama yaitu sensorMQ-136, sensor Mikrofon, sensor DHT22danrangkaian pengendali mikro sebagai pembacaan data dari setiap sensor serta rangkaian modul penunjang. Semua modul dirancang melalui software Eagle kemudian dicetak pada papan print circuit board (PCB) satu lapisan dengan metode etching menggunakan larutan $\mathrm{FeCl}_{3}$. Setiap modul dikemas di dalam kotak yang akan difasilitasi power supply 5 V 2 A dan kipas pendingin. Permukaan bagian atas kotak diberi label skematik rangkaian sesuai dengan skematik pada masing-masing modul sensor dan pengendali mikro.

\section{Perancangan Minimum Sistem Pengendali Mikro}

Pengendali mikro yang digunakan adalah minimum sistem arduino uno. Minimum sistem ini memiliki 22 pin yang terdiri dari: pin I/O digital, pin input analog, pin sumber daya $5 \mathrm{~V}$ dan pin ground. Pin I/O digitalakan diberi nomor D0 sampai D13, semua pin dapat dijadikan sebagai input ataupun otput melalui program Arduino IDE. Sejumlah pin digital yaitu D3, D5, D6, D9, D10 dan D11 dapat diprogram kembali menjadi pin output analog atau diistilahkan sebagai PWM (Pulse Width Modulation). Pin input analog diberi nomor A0 sampai A5, semua pin dapat membaca nilai analog $\left(V_{\text {analog }}\right)$ dan mengkonversikan nilai tersebut menjadi nilai ADC (Analog to Digital Analog) dalam rentang $0-1023$ melalui Persamaan 1. Nilai ADC dapat merepresentasikan sinyal yang diterima oleh sensor analog dan dapat diubah ke nilai - nilai tertentu seperti konsentrasi gas. 


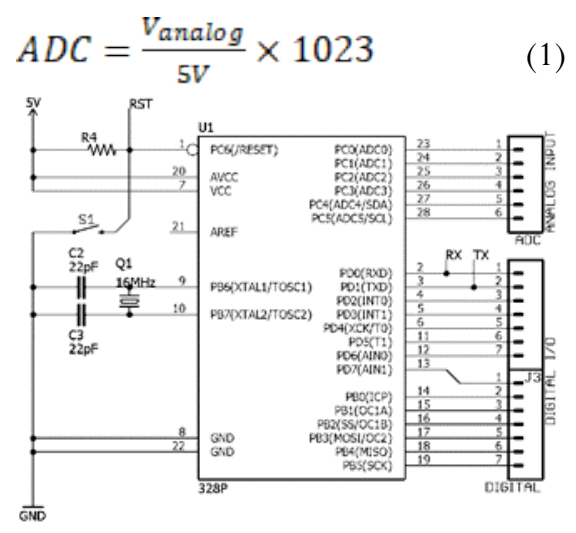

Gambar 1. Skematik Rangkaian minimum system Arduino Uno.

\section{Perancangan Modul Sensor Gas MQ-136}

Sensor gas MQ-136dihubungkan dengan resistor 10Kohm. Tegangan sumber yang diperlukan dalam pengoperasian sensor adalah $5 \mathrm{~V}$. Kalibrasi tiap sensor perlu dilakukan terhadap berbagai jenis gas diantaranya gas $\mathrm{CO}, \mathrm{SO}_{2}$ dan CH4. Pin tegangan output sensor MQ-136 dihubungkan dengan minsis arduino melalui pin analog. Program Arduino IDE dirancang untuk mengubah nilai ADC yang diterima menjadi konsentrasi gas dalam satuan ppm.

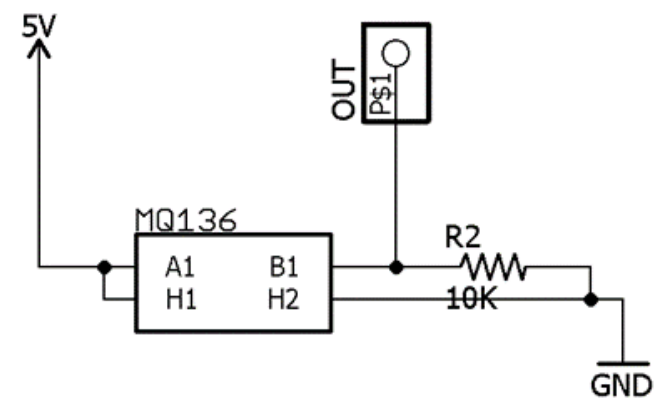

Gambar 2. Skematik rangkaian sensor MQ-136

\section{Perancangan Modul Sensor Mikrophone/ Sensor Akustik}

Sensor microphone dihubungkan menggunakan rangkaian OP-AMP (Operasional Amplifier) agar dapat digunakan dalam berbagai aplikasi yang menggunakan suara sebagai objek yang akan dideteksi. Output yang dihasilkan berupa frekuensi, sehingga intensitas suara dapat program pada arduino IDE. Sensor ini memiliki 3 pin yaitu VCC, GND dan OUTPUT dengan tegangan operasi sebesar $5 \mathrm{~V}$. Output sensor nantinya akan dihubungkan pada PIN digital sebagai input sehingga dapat dibaca sebagai frekuensi.

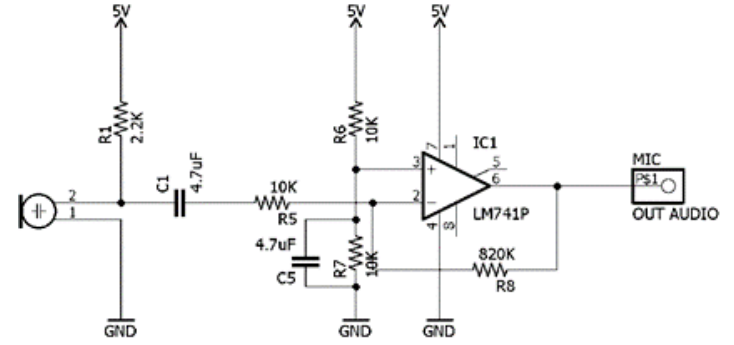

Gambar 3. Skematik rangkaian sensor microphone

\section{Perancangan Modul Sensor Suhu dan Kelembaban DHT22}

Modul sensor suhu dan kelembaban DHT22 dirancang agar dapat digunakan untuk mengukur suhu dan kelembaban baik. DHT22 memiliki 4 pin yaitu VCC, DATA, NC (not connected), dan GND. Pin VCC DHT dihubungkan dengan pin $5 \mathrm{~V}$ pada minsis arduino, sedangkan pin DATA dihubungkan ke D3 melalui resistor 4.7 Kohm, dan pin GND sensor dihubungkan dengan pin ground. Dalam pengoperasian sensor DHT melalui program IDE, dibutuhkan library DHT. Waktu pencuplikan data kelembaban dan suhu dilakukan dengan interval 1 detik.

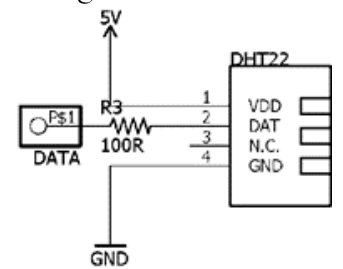

Gambar 4.Skema rangkaian sensor DHT22 6. Perancangan Modul Penunjang

Ada beberapa modul penunjang yang akandimasukkan kedalam trainer kit seperti LCD 16x2, buzzer, RTC(Real Time Clock) DS1307 dan SD Card. LCD 16x2 ditambahkan sebagai layar display nilai keluaran tiap sensor yang sedang diaktifkan. Buzzer digunakan sebagai pemberi peringatan jika bacaan sensor melebihi nilai yang ditetapkan dalam program Arduino IDE. Frekuensi suara yang akandikeluarkan oleh buzzer dapat disesuaikan menggunakan program Arduino IDE. RTC merupakan pewaktu yang ditambahkan untuk mencatat waktu secara simultan. SD Card digunakan sebagai tempat menyimpan data bacaan sensor. Semua modul penunjang ditambahkan pada modul trainer kit sebagai pelengkap operasional kerja sehingga trainer kit dapat digunakan secara optimal. Sama seperti sensor utama, setiap modul penunjang harus di uji apakah dapat bekerja dengan baik atau tidak. 


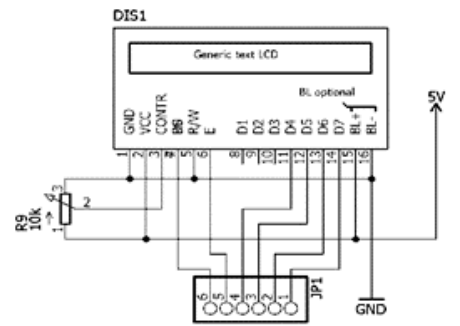

Gambar 5. Skema LCD 16x2

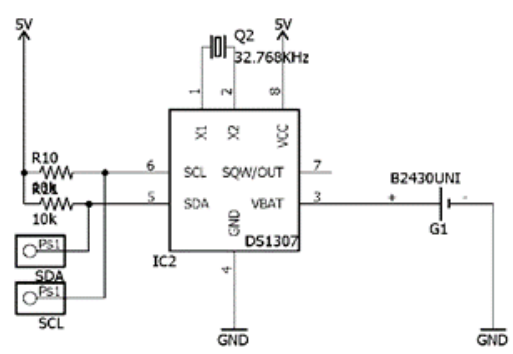

Gambar 6. Skema RTC DS1307

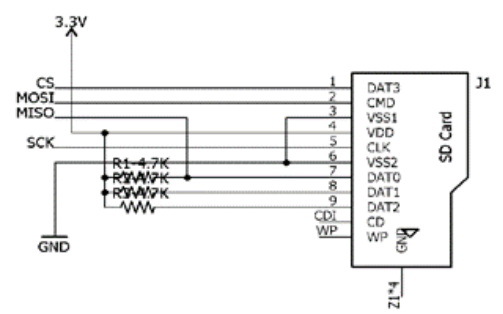

Gambar 7. Skema SD Card

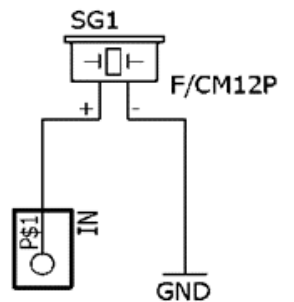

Gambar 8. Skema Buzzer

\section{HASIL DAN PEMBAHASAN}

Trainer kit HTNSJR2018A telah dilengkapi dengan berbagai komponen elektronika dan sensor. Gambar 9 menunjukkan tampilan trainer kit HTNSJR2018A yang masih dalam tahap pengujian. Rangka luar trainer kit terbuat dari kaca akrilik, dimana tiap modul ditempatkan didalamnya dan difasilitasi dengan sumber daya dan kipas pendingin.

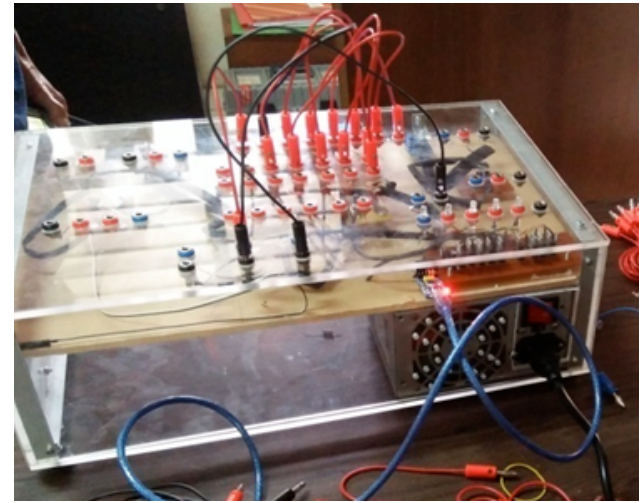

Gambar 9.Trainer kit HTNSJR2018A

\section{Pengujian RTC}

Sistem RTC dapat memperoleh data berupa tanggal, hari dan jam. Hasil pengujian RTC ditunjukkan pada Tabel 1. Berdasarkan Tabel terlihat bahwa RTC mampu mencatat waktu setiap 1 detik, sehingga data waktu tersebut dapat digunakan pada pengoperasian sensor. Penyusunan tanggal memiliki format DD/MM/YYYY dan jam dalam format $\mathrm{HH}: \mathrm{MM}$ :SS.

Tabel 1. Data pengujian RTC

\begin{tabular}{lll}
\hline Tanggal & Hari & Jam \\
\hline $13 / 8 / 2018$ & Senin & $14: 37: 59$ \\
\hline $13 / 8 / 2018$ & Senin & $14: 38: 00$ \\
\hline $13 / 8 / 2018$ & Senin & $14: 38: 01$ \\
\hline $13 / 8 / 2018$ & Senin & $14: 38: 02$ \\
\hline $13 / 8 / 2018$ & Senin & $14: 38: 03$ \\
\hline $13 / 8 / 2018$ & Senin & $14: 38: 04$ \\
\hline $13 / 8 / 2018$ & Senin & $14: 38: 05$ \\
\hline $13 / 8 / 2018$ & Senin & $14: 38: 06$ \\
\hline $13 / 8 / 2018$ & Senin & $14: 38: 07$ \\
\hline $13 / 8 / 2018$ & Senin & $14: 38: 08$ \\
\hline
\end{tabular}

\section{Pengujian Sensor Suhu dan Kelambaman}

Sensor suhu dan kelembaman yang digunakan dalam pengujian ini adalah sensor DHT22. Pengujian pada sensor suhu dan kelembaman ini dilakukan di rungan laboratorium. Pada Gambar 10 menunjukkan grafik pengujian sensor suhu dan kelembaman saat berada pada suhu ruangan atau saat sensor tidak diberi perlakuan apapun, hanya mengukur suhu ruangan di laboratorium. Pada Gambar 10 data berada pada rentang $0-155$ sekon. Terlihat bahwa suhu pada ruangan laboratorium berada di kisaran $28,8{ }^{\circ} \mathrm{C}$. Sedangkan, kelembaban ruangan berada di kisaran $75 \%$. Berdasarkan data terlihat bahwa kisaran suhu di ruangan cenderung konstan dan tidak mengalami perubahan secara signifikan. Demikian juga halnya dengan kelembaban. 


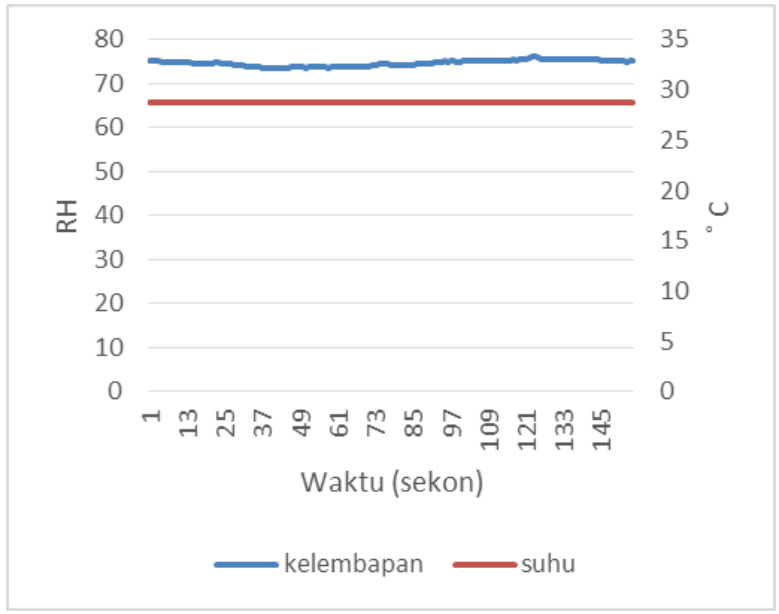

Gambar 10. Grafik pengujian sensor DHT22 pada suhu ruangan

Selanjutnya sensor DHT22 diuji dengan memberikan udara hangat dari hembusan nafas manusia. Hasil uji ditunjukkan pada Gambar 11, pada rentang waktu $0-370$ detik. Pada detik ke -0 hingga 53 detik sensor masih mendeteksi suhu udara biasa di ruangan laboratorium. Kemudian pada detik 54 sensor mulai diberi hembusan nafas manusia. Sehingga, sensor mendeteksi suhu yang perlahanlahan naik dan kelembaban yang terdeteksipun meningkat. Pada detik $86-89$ suhu yang terdeteksi mencapai nilai maksimum. Kemudian pada detik ke 90 hembusan tidak lagi diberikan sehingga suhu perlahan-lahan mulai turun dan kelembaban juga mulai turun.

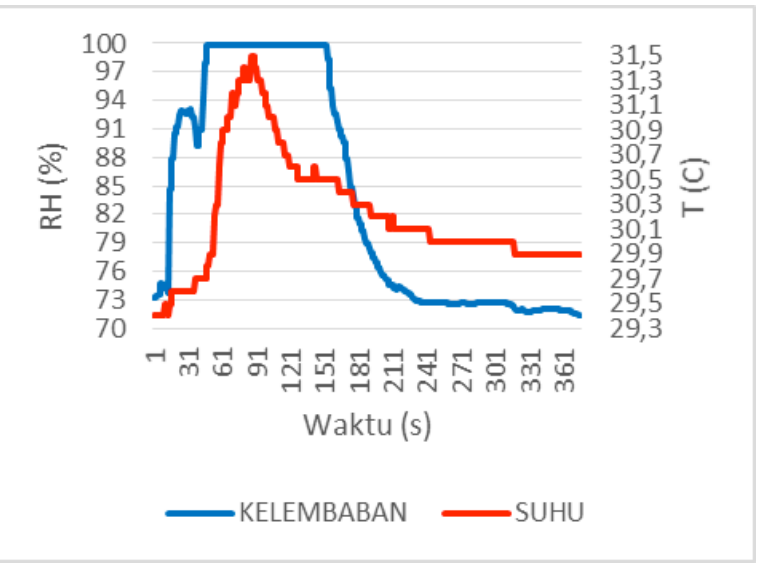

Gambar 11. Grafik pengujian sensor DHT22 saat diberi hembusan nafas manusia

Selanjutnya sensor DHT22 diuji dengan memberikan udara hangat dengan diberi panas dari hairdryer. Hasil uji ditunjukkan pada Gambar 12, pada rentang waktu 0 - 683 sekon. Pada detik ke 0 hingga 9 sensor masih mendeteksi suhu udara biasa di ruangan laboratorium. Kemudian pada detik 10 sensor mulai diberi hembusan panas dari hairdryer. Sehingga, sensor mendeteksi suhu yang perlahan- lahan naik dan kelembaban yang terdeteksipun menurun. Pada detik $43-75$ suhu yang terdeteksi mencapai nilai maksimum yaitu sekitar $43^{\circ} \mathrm{C}$. Sedangkan, untuk kelembaban mengalami penurunan terendah di detik ke 69 - 84 yaitu kisaran 40\%. Kemudian pada detik ke 111 hembusan dari hairdryer tidak lagi diberikan sehingga suhu perlahan-lahan mulai turun dan kelembaban juga mulai turun. Berdasarkan data Gambar 11, diketahui sensor DHT22 telah mampu memberikan respon saat kondisi suhu dan kelembaban di lingkungan sekitar sensor diubah. Perlakuan pemberian panas berupa hembusan dari hairdryer menyebabkan suhu disekitar sensor meningkat dan kelembaban menurun.

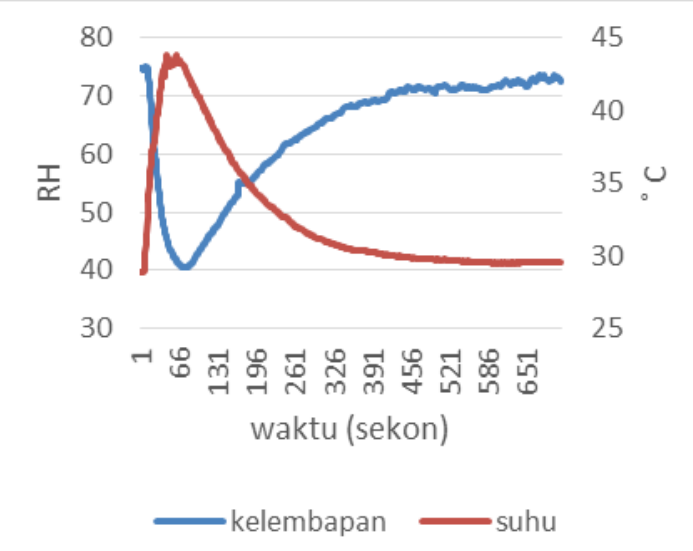

Gambar 12. Grafik pengujian sensor DHT22 saat diberi udara dari hairdyer

Kemudian sensor DHT22 diuji dengan memberikan aliran panas dari korek api. Gambar 13 menunjukkan grafik pengujian sensor DHT22 saat diberi aliran panas dari korek api. Pada rentang $0-$ 36 detik sensor masih belum diberi aliran panas. Pada detik ke 37 sensor mulai dipapar aliran panas dari korek api dan terlihat sensor mendeteksi suhu yang mulai meningkat. Hingga mencapai suhu maksimum sebesar $36^{\circ} \mathrm{C}$ hingga detik ke 192 . Kemudian pada detik ke 193 aliran panas mulai dihilangkan sehingga suhu yang terdeteksi oleh sensor perlahan-lahan menurun. Sementara kelembaban ketika pengaruh aliran panas dari korek api diberikan, kelembaban mengalami penurunan dan saat pengaruh alirah panas dihilangkan perlahanlahan kelembaban yang dideteksi meningkat. 


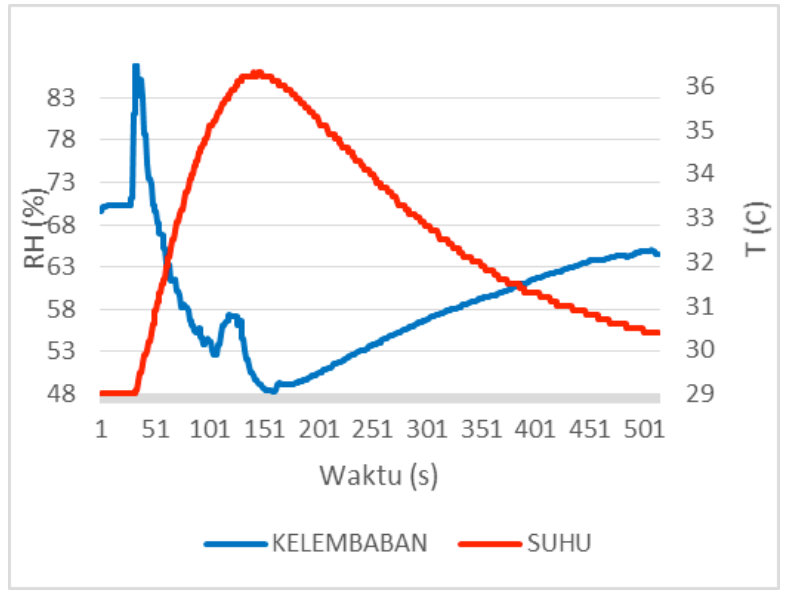

Gambar 13. Grafik pengujian sensor DHT22 saat diberi panas dari korek api

\section{Pengujian Sensor Gas MQ136}

Sensor MQ136 diuji menggunakan gas $\mathrm{SO}_{2}$ yang bersumber dari pembakaran belerang. Data hasil pengujian ditampilkan pada Gambar 18 . Fluktuasi data menunjukkan bahwa sensor MQ136 sensitif terhadap perubahan konsentrasi gas $\mathrm{SO}_{2}$. Nilai respon terendah diperoleh pada tegangan 0,79 $\mathrm{V}$ dan nilai tegangan tertinggi diperoleh pada 1,7 V. Ketika sensor dipapar dengan $\mathrm{SO}_{2}$ maka bacaan tegangan akan meningkat dapat dilihat pada waktu 0 - $20 \mathrm{~s}$, tegangan tertinggi dihasilkan pada waktu 20 s dengan besar tegangan 1,7 V, dan waktu 21-106 $\mathrm{s}$ tegangan gas mulai menurun, hal ini sesuai dengan pengujian yang dilakukan, dimana gas $\mathrm{SO}_{2}$ yang di paparkan mulai habis.

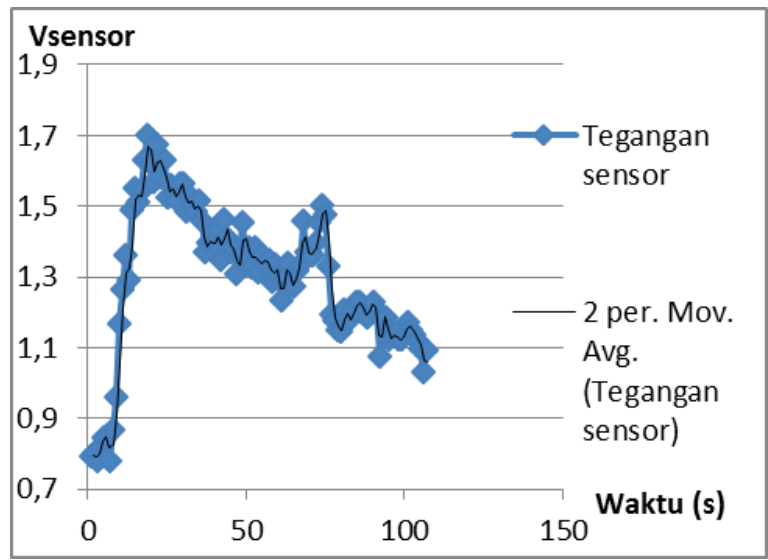

Gambar 14. Grafik waktu respon sensor MQ136 terhadap tegangan sensor gas $\mathrm{SO}_{2}$

Hubungan antara perubahan resistansi terhadap konsentrasi gas (ppm) dapat dilihat pada Gambar 15. Nilai konsentrasi gas dalam part per million (ppm) $\mathrm{SO}_{2}$ akan diperoleh dengan cara mengambil beberapa data Rs (resistansi sensor MQ136 terhadap konsentrasi gas yang berbeda) dan dicari persamaan garisnya terhadap setiap perubahan konsentrasi gas $\mathrm{SO}_{2}$. Pada Gambar 19dapat dilihat bahwa hubungan antara resistansi dengan konsentrasi gas dalam ppm adalah berbanding terbalik. Pada resistansi yang kecil di peroleh konsentrasi yang besar, yaitu pada 9037 ohm memiliki konsentrasi gas tertinggi pada 70,99 ppm dan pada resistansi sensor yang paling besar 25163 ohm memiliki nilai konsentrasi gas yang paling rendah 32,49 ppm. Hal tersebut sangat sesuai dengan grafik karakteristik yang terdapat pada datasheet sensor MQ136.

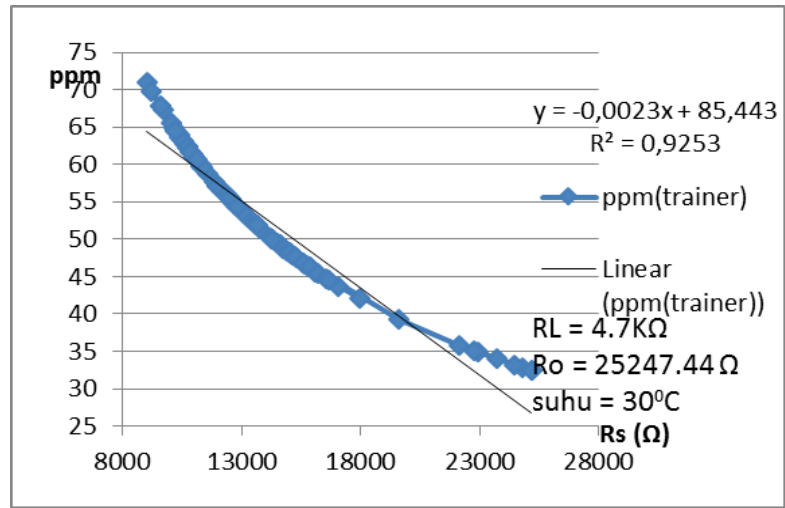

Gambar 15. Grafik perubahan Rs terhadap konsentrasi gas $\mathrm{SO}_{2}$

Grafik pada Gambar 16 merupakan grafik perubahan resistansi terhadap perubahan konsentrasi gas $\mathrm{SO}_{2}$, sumbu y mewakili Log (Rs/Ro) dengan Rs merupakan nilai resistansi yang terukur oleh sensor MQ136 pada berbagai konsentrasi gas $\mathrm{SO}_{2}$, dan Ro merupakan nilai resistansi sensor MQ136 yang bernilai 21,45. Sedangkan sumbu $\mathrm{x}$ mewakili konsentrasi gas $\mathrm{SO}_{2}$ dalam satuan ppm. Pada Gambar 16 terlihat bahwa saat rasio resistansi mengalami peningkatan,yang mengakibatkan konsentrasi yang terdeteksi oleh sensor mengalami penurunan. Keberadaan gas disekitar sensor yang semakin berkurang menyebabkan konsentrasi gas menurun. Oleh sebab itu, saat sensor mendeteksi penurunan konsentrasi gas tersebut, respon yang ditunjukkan adalah dengan menurunnya tegangan dan menurunnya rasio resistansi pada sensor. Rasio resistansi sensor akan bernilai $\approx 1$ di saat konsentrasi gas $\mathrm{SO}_{2} \approx 30 \mathrm{ppm}$. Rumus untuk mencari nilai ppmini dapat diperoleh dari persamaan polynomial dengan menggunakan analisis trendline, yaitu $p p m=31,89\left(R_{s} / R_{o}\right)^{0,75}$ dan deviasinya adalah $R^{2}=0,998$. 


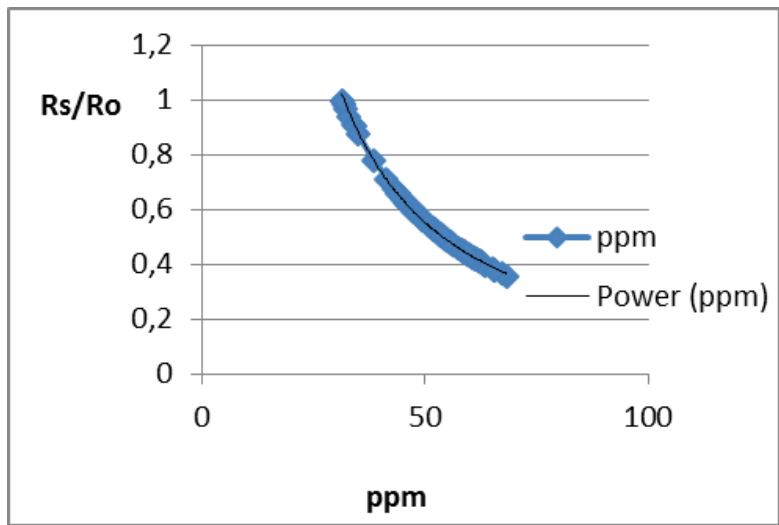

Gambar 16. Grafik perubahan resistansi terhadap konsentrasi gas $\mathrm{SO} 2$

Gambar 17 menunjukkan grafik perubahan tegangan sensor terhadap rasio resistansi. Pada Gambar terlihat bahwa rasio resistansi cenderung mengalami penurunan seiring dengan meningkatnya tegangan. Penentuan nilai rasio resistansi dapat dilakukan dengan persamaan polynomial dengan menggunakan trendline, yakni $R_{s} / R_{o}=0,661(V)+1,406$ dan dengan deviasi $R^{2}=0,943$.

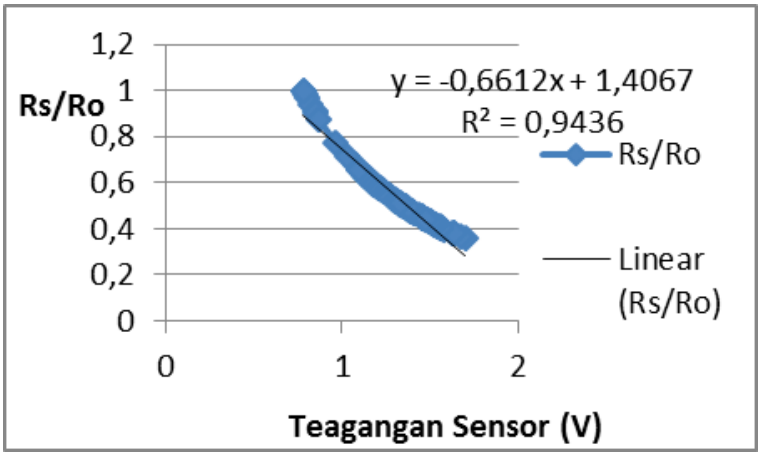

Gambar 17. Grafik perubahan tegangan sensor terhadap rasio resistansi

\section{Pengujian Sensor Microphone}

Sensor akustik atau sensor microphone diuji dengan beberapa perlakuan, yang pertama adalah dengan memberikan suara dari sebuah nada dengan volume yang kecil. Berdasarkan grafik yang ditunjukkan pada Gambar 18 terlihat bahwa sensor sudah dapat memberikan respon saat dibunyikan nada tersebut. Terlihat pada interval waktu $2000-$ 12000 (10 ms) terdapat peningkatan respon tegangan dari sensor. Walaupun, cukup terlihat jelas bahwa respon tegangan yang diberikan tidak signifikan. Hal itu disebabkan volume bunyi nada tersebut dalam volume yang kecil, sehingga respon tegangan yang diberikan tidak berbeda jauh jika dibandingkan sebelum sensor diberi pengaruh luar berupa suara dari sebuah nada. Selain itu, respon yang terlihat adalah sinyal dalam bentuk gelombang bunyi atau suara.

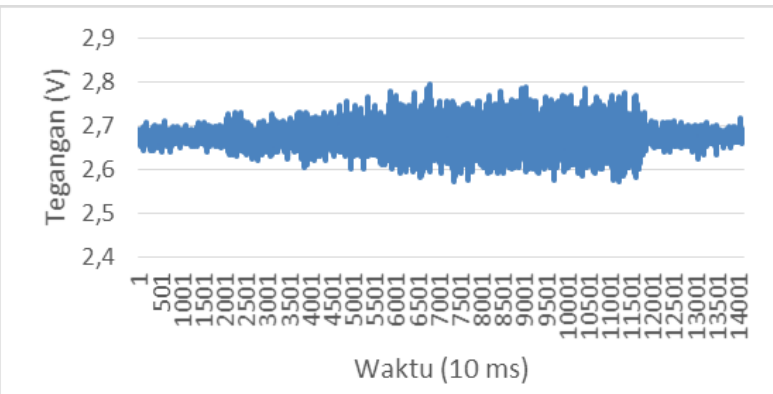

Gambar 18. Respon sensor akustik terhadap nada dengan volume kecil

Selanjutnya, sensor akustik ini diuji dengan memberikan suara dari nadayang sama tapi dengan volume suara yang lebih besar. Pada Gambar 19, terlihat respon yang diberikan sensor berbeda dengan Gambar 18. Pada rentang waktu $2000-$ 11500 (10 ms) terdapat peningkatan respon tegangan yang cukup sigfinikan. Hal ini disebabkan volume nada yang dibunyikan cukup tinggi, sehingga respon tegangan mengalami perubahan yang cukup signifikan dibandingkan sebelum sensor diberi pengaruh berupa suara dari nada tersebut.

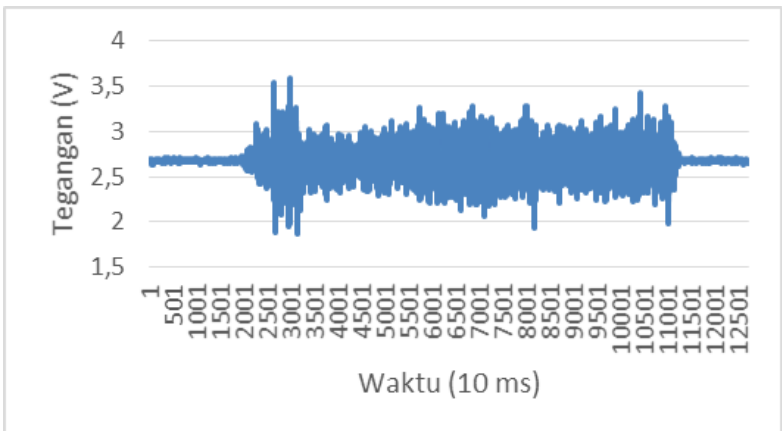

Gambar 19. Respon sensor akustik terhadap nada dengan volume tinggi

Berdasarkan respon yang ditunjukkan dari kedua Gambar di atas, maka dapat diketahui bahwa sensor akustik atau sensor microphone yang digunakan dalam trainer kit ini dapat bekerja dengan baik. Sensor akustik pada trainer kit sudah mampu mendeteksi dan merespon kebisingan dilingkungan sekitar trainer kit.

\section{KESIMPULAN DAN SARAN}

Berdasarkan penelitian yang telah dilakukan maka dapat disimpulkan bahwa trainer kit HTNSJR2018A telah berhasil dibuat dan Sensor suhu dan kelembaban telah bekerja dengan baik ditunjukkan dengan adanya perubahan respon saat sensor dipaparkan pengaruh berupa hembusan nafas, udara dari hairdyer dan aliran panas dari korek api. 
Sedangkan untuk sensor gas MQ136 juga telah bekerja dengan baik ditunjukkan dengan adanya perubahan respon berupa tegangan dan rasio resistansi dari sensor saat dipaparkan gas $\mathrm{SO}_{2}$ yang dihasilkan dari belerang. Kemudian, untuk sensor akustik/microphone juga telah dapat bekerja dengan baik ditunjukkan dari perubahan tegangan saat diberi nada dengan volume rendah dan volume tinggi.

\section{DAFTAR PUSTAKA}

Hasan, S., 2006, Analisa Perakitan Trainer Unit Berdasarkan Aplikasi Konsep Refrigerasi pada Mata Kuliah Sistem Pendingin (Bahan Kuliah). Bandung: UPI..

Ristiana, R., 2013, Sistem Monitoring Gas $\mathrm{SO}_{2}$ pada Proses Pengolahan Bijih Gelena, Prosiding Semirata FMIPA Universitas Lampung, 141-145

Treska, F., 2013, Rancang Bangun Warning System dan Monitoring Gas Sulfur Dioksida $\left(\mathrm{SO}_{2}\right)$ Gunung Tangkuban Perahu Via SMS Gateway Berbasis Mikrokontroler Menggunakan Sensor MQ-136, Telekontran, Vol. 1 No. 2, pp 63-72 